\title{
A percepção dos paulistas sobre a realização dos verbos pronominais
}

\author{
Aline Camila Lenharo \\ Universidade Estadual Paulista "Júlio de Mesquita Filho" (UNESP), \\ Araraquara, São Paulo, Brasil \\ alenharo@hotmail.com
}

DOI: http://dx.doi.org/10.21165/el.v46i1.1699

\begin{abstract}
Resumo
Este artigo apresenta dados heurísticos e empíricos sobre a percepção que um grupo de paulistas possui em relação à realização dos verbos pronominais (VP), especialmente os classificados como verbo $+\mathrm{SE}_{\text {inerente. }}$ É motivado pelo fato de, no Brasil, haver peculiaridades (mesmo que consideradas marginais) relacionadas ao uso do clítico dos VP - tal como a possibilidade de supressão do clítico, como em "eu apaixonei por você" - que distinguem o português brasileiro da língua portuguesa falada em outras regiões do mundo, havendo diferenças mesmo dentro do país. Fundamenta-se em trabalhos variacionistas que procuram explicar essas peculiaridades em diferentes regiões do Brasil e em dados oriundos da aplicação de um questionário online. Através da observação dos dados, espera-se apontar para uma mudança linguística possivelmente em curso no português do Brasil.
\end{abstract}

Palavras-chave: verbos pronominais; clítico SE inerente; variação.

\section{Paulistas' perception on the realization of pronominal verbs}

\begin{abstract}
This paper presents heuristic and empirical data on the perception that a group of speakers from São Paulo state has on the achievement of pronominal verbs (PV), especially those classified as verb $+\mathrm{SE}_{\text {inherent. }}$ It is motivated by the fact that, in Brazil, there are peculiarities (even considered marginal) related to the use of clitic from PV - such as the possibility of clitic suppression, as in "eu apaixonei por você" ('I fell in love with you') - that distinguish Brazilian Portuguese language from Portuguese language spoken in other regions of the world (note that there are differences within the country). It is based on variationist works that seek to explain these peculiarities in different regions of Brazil and in data from the application of an online questionnaire. Through the data observation, it is expected to point out for a linguistic change possibly underway in Brazilian Portuguese.
\end{abstract}

Keywords: pronominal verbs; clitic SE inherent; variation.

\section{Introdução}

A linguagem constitui a capacidade que os seres humanos possuem para se comunicar (por meio de palavras, gestos, imagens, sons, expressões, etc.) - ou, em outras palavras, para produzir, desenvolver e compreender a língua e outras manifestações comunicativas (como a dança e o cinema mudo, por exemplo) - e se realiza historicamente. O mesmo ocorre com as línguas naturais, que podem ser consideradas instrumentos destinados à obtenção da interação social entre falantes de determinada comunidade linguística e são vinculadas à vida social e cultural desses falantes (BAKHTIN, 1986, 2015). 
Embora historicamente realizadas, as línguas não são estáticas: são realidades dinâmicas que mudam, ao longo do tempo, de modo lento e gradual. Muitas vezes, essas mudanças, por atingirem partes da língua (e não o todo), não são percebidas pelos falantes (LABOV, 1994, 2008; TARALLO, 1994). No entanto, podem ser observadas quando, por exemplo, há contato: com textos muito antigos (escritos há diversos anos); entre diferentes gerações; entre pessoas pertencentes a grupos sociais distintos; entre pessoas com níveis diferentes de escolarização (FARACO, 2014), entre outros. São situações que comprovam a transformação pela qual a língua passa com o desenrolar do tempo, evidenciando que estruturas e itens lexicais que "existiam antes não ocorrem mais ou estão deixando de ocorrer", ou, então, ocorrem com modificação "em sua forma, função e/ou significado" (FARACO, 2014, p. 16).

É importante ressaltar que existem variações linguísticas, caracterizadoras dos diferentes grupos de fala existentes em determinada comunidade, que, em princípio, não configuram mudança linguística: nem toda variação na estrutura linguística implica mudança, mas toda mudança pressupõe variação (FARACO, 2014; TARALLO, 1994; WEINREICH; LABOV; HERZOG, 2006). Em outras palavras, "a língua é uma realidade heterogênea, multifacetada e [...] as mudanças emergem dessa heterogeneidade, embora de nem todo fato heterogêneo resulte necessariamente mudança" (FARACO, 2014, p. 2324).

A tendência é a de que os elementos linguísticos inovadores ocorram com maior frequência na fala das gerações mais novas e na dos grupos socioeconômicos menos favorecidos (FARACO, 2014; LABOV, 1994). Esse fator, somado ao fato de serem peculiaridades que fogem à norma culta da língua, faz com que, muitas vezes, as variações sejam socialmente estigmatizadas e marginalizadas. É o que ocorre, por exemplo, com as variações de uso do clítico SE do português.

Ao se comparar a língua portuguesa de Portugal e a do Brasil, país colonizador e país colonizado - que teve influência linguística de diversas culturas indígenas, africanas e imigrantes europeus -, é possível citar inúmeras peculiaridades que distinguem o português brasileiro (PB) do português lusitano (PP). Algumas dessas peculiaridades são concernentes ao uso do clítico pronominal, tais como a neutralização do clítico na forma de terceira pessoa (se) para todas as pessoas verbais (01) e a tendência de apagamento dos clíticos - como ocorre com o $\mathrm{SE}_{\text {reflexivo }}(02)$ e o $\mathrm{SE}_{\text {inerente }}$ (03), por exemplo (GALVES, 2001; OLIVEIRA, 2006; PEREIRA, A., 2006; PEREIRA, D., 2007; VILELA, 1995). ${ }^{1}$

(01) Eu se sinto feliz.

(02) Cai da bicicleta e Ø machuquei.

(03) Eu Ø apaixonei por você.

Em relação aos percentuais de realização e de supressão dos clíticos $\mathrm{SE}_{\text {reflexivo }} \mathrm{e}$

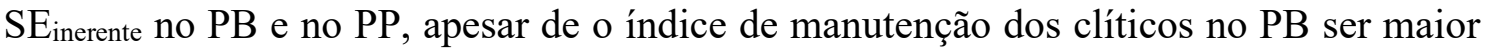
que o do apagamento, como no PP, com $51 \%$ de manutenção (49\% de apagamento) do

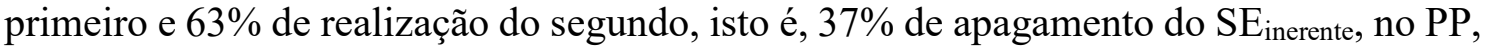

\footnotetext{
${ }^{1}$ O SE representa todas as formas conjugadas (em número e pessoa) do clítico: me, te, se, nos, vos e $s e$.
} Sobre os diferentes tipos de clítico SE, consultar Nunes (1990) e Lenharo (2014). 
a preferência pela realização do clítico é bem mais acentuada, com $90 \%$ de manutenção do $\mathrm{SE}_{\text {reflexivo }}$ e $100 \%$ de realização do $\mathrm{SE}_{\text {inerente }}$ (MELO, 2005).

Diferenças intercontinentais, como essas, no comportamento do uso do clítico SE, podem ser verificadas mesmo dentro do Brasil, dada a grande extensão territorial do país. Por exemplo, enquanto na região Sudeste a tendência mais forte é a do apagamento do clítico, há uma tendência de conservação do clítico na região Nordeste, havendo, inclusive, a extensão do clítico na fala nordestina, com a realização dupla do clítico SE (D’ALBUQUERQUE, 1984; GALVES, 2001; MELO, 2005; OLIVEIRA, 2006).

Este artigo, além desta introdução, apresentará o estudo de trabalhos variacionistas (GONDIM, 2011; MELLO, 2009; MELO, 2005; NUNES, 1995; RODRIGUES; PEREIRA, 2005; entre outros) que procuram explicar as peculiaridades do uso do clítico SE em diferentes regiões do Brasil. Esse panorama a ser traçado pode contribuir para a sistematização dos usos não prototípicos dos verbos pronominais no PB. Em seguida, serão apresentados dados oriundos da aplicação de um questionário online, realizado com falantes do interior do estado de São Paulo, por meio do site SurveyMonkey. Por fim, através da relação desses dados heurísticos e empíricos, esperase apontar para uma mudança linguística possivelmente em curso no PB.

\section{Diferentes usos do clítico SE no Brasil}

Há, como mencionado, algumas peculiaridades no uso do clítico pronominal no PB que o diferenciam da língua portuguesa falada em outros países, havendo, inclusive, variações de uso dentro do país. Os parágrafos subsequentes fornecem as conclusões de pesquisadores de diferentes regiões do Brasil acerca do uso do clítico SE, ilustrando as diferenças linguísticas regionais.

Na região Nordeste, há uma tendência de conservação do clítico, havendo também sua extensão - com a realização dupla do clítico SE. No estado da Paraíba, especificamente, verifica-se uma alta frequência de sua utilização: $85 \%$ de manutenção e $15 \%$ de supressão do clítico $\mathrm{SE}$, sendo esta associada, em sua maioria, com verbos transitivos - pois a possibilidade de apagamento do Objeto Direto na forma não pronominal do verbo viabilizaria o apagamento do Complemento sob a forma de clítico pronominal (MELLO, 2009).

Verifica-se, entretanto, na cidade de Fortaleza (estado do Ceará), a supressão do SE, com $57 \%$ de índice de apagamento. Essa supressão é maior entre os informantes mais velhos - o que pode ser um indicativo de que a mudança linguística de apagamento do SE esteja se implantando há algum tempo. Por outro lado, entre os informantes mais jovens, o índice de utilização do SE é maior - o que pode ser um sinal de que o ápice da não utilização do SE já tenha ocorrido, havendo a possibilidade da volta de seu uso (GONDIM, 2011). Não se pode afirmar, no entanto, se a população mais jovem de Fortaleza tem empregado o clítico pronominal de maneira idêntica aos usos canônicos do SE ou se novas regras de utilização estão sendo estabelecidas.

Por sua vez, a duplicação do clítico SE na fala nordestina tende a ocorrer com verbos conjugados na terceira pessoa do singular do Pretérito Perfeito do Indicativo, como em (04), servindo como "marca de oralidade" ou como "leitura resultativa do evento": enquanto o SE proclítico possui traços de reflexividade, isto é, é um SE reflexivo, o enclítico serve "como uma marca morfológica de aspecto" (OLIVEIRA, 2006, p. 6-7). 
A duplicação do clítico SE é uma realização que não se adéqua à norma culta da língua e (como salientado anteriormente) é socialmente estigmatizada e marginalizada, assim como as demais variações de uso do clítico. Como consequência desse desvio da norma, tem-se ponderado sobre a influência da escolarização (ou da falta dela) nos fenômenos concernentes ao uso do SE com bastante frequência. Isso porque, além de fatores internos ao sistema linguístico, como, por exemplo, o tipo do clítico SE e o tipo de verbo com que o clítico se realiza na construção, os fatores sociais, externos ao sistema, tais como o nível de escolarização, o poder aquisitivo, o sexo, a faixa etária e a origem do informante, influenciam na variação linguística (LABOV, 1994, 2001, 2006, 2008; MONTEIRO, 2002; TARALLO, 1994).

Entre os linguistas (D’ALBUQUERQUE, 1984; GALVES, 2001; MELO, 2005; OLIVEIRA, 2006), é consenso, por exemplo, que, na região Sudeste do Brasil, a supressão do clítico SE é mais comum entre os falantes de Minas Gerais (MG), onde o apagamento do clítico ocorre em favor do uso da categoria vazia, independentemente da tipologia do clítico e da classe social do falante. Em relação ao nível de escolaridade, há quem defenda que o apagamento do SE é um fenômeno independente deste fator, com supressão generalizada do clítico (D'ALBUQUERQUE, 1984), e quem argumente que o nível de escolaridade influencia na sua manutenção/apagamento - com índices de manutenção maiores entre os falantes mais jovens (de classe social alta) que cursaram ou estão cursando o ensino superior (MELO, 2005).

Em relação a São Paulo, Nunes (1995) defende que a escolaridade do falante influencia na variação do uso do SE, sendo menor a supressão entre os que possuem nível superior. Segundo o autor, a manutenção/apagamento do clítico também varia conforme o tipo de texto/discurso, sendo sua manutenção avaliada positivamente em São Paulo, ainda que sua ausência não seja estigmatizada.

$\mathrm{Na}$ região Sudeste do Brasil, especificamente no estado de $\mathrm{MG}$, a análise diacrônica da frequência de uso dos diferentes tipos de SE mostra uma diminuição do uso de todos os tipos de clítico pronominal, principalmente em contextos orais. De acordo com as conclusões de D'Albuquerque (1984) e Lima (2006):

- $\mathrm{O}$ apagamento do $\mathrm{SE}_{\text {reflexivo }}$ é validado pela interpretação contextual do discurso, isto é, devido à previsibilidade semântica do Complemento, a realização do Objeto Nulo é permitida. Além do uso da categoria vazia, quando a construção atualiza o SEreflexivo com traço de reciprocidade, o SE tende a ser substituído por expressões não pronominais, tais como "ele mesmo" e "um com o outro".

- O SE inerente, por ser adquirido pelo falante através dos moldes lexicais da memorização, apesar de sofrer o apagamento, tende a ser o tipo de clítico SE mais utilizado.

- Paralelamente ao fenômeno da supressão de diversos tipos de SE (verificada em contextos oral e escrito informal), verifica-se um aumento na frequência de uso do $\mathrm{SE}_{\text {indeterminado }}$ (em contexto escrito formal argumentativo) devido ao aumento do número de textos acadêmicos, como teses e dissertações.

Em relação à área colonizada pelos Bandeirantes paulistas, que abrange a zona rural dos estados de São Paulo (SP) e de Minas Gerais (MG), com foco nos informantes 
adultos analfabetos (ou com baixo nível de escolarização) e de baixa renda (do interior dos estados), Rodrigues e Pereira (2005) concluem que:

- Há um alto índice de supressão do SE, 75\%, tendo sido realizados em 199 ocorrências (de 802 analisadas).

- Quando o SE é atualizado, há uma generalização da forma se para a Primeira Pessoa do plural (nós) em detrimento de nos, como em (05). De acordo com Oliveira (2005), essa neutralização do clítico em relação às marcas de pessoa e de número, típica da região Nordeste, teria se disseminado, especialmente para o Sudeste do país, devido ao grande número de migrantes que saíram do Nordeste em direção a SP. Mas, devido aos processos de Gramaticalização aos quais os clíticos estão sujeitos, é possível, atualmente, observar a neutralização do SE, em contextos informais de fala, em praticamente toda a extensão territorial brasileira (CASTILHO, 1997).

“ma depois que nóis brigamo nóis si largamo..." (RODRIGUES; PEREIRA, 2005, p. 1-2).

- Os seis fatores que influenciam na variação do uso do SE, em ordem de relevância, são: (a) o tipo do clítico; (b) a idade do informante; (c) o estatuto gramatical do SE; (d) o papel semântico do Sujeito; (e) o sexo do informante; (f) o local de residência do informante (RODRIGUES; PEREIRA, 2005).

Diferentemente do que defende D'Albuquerque (1984), Rodrigues e Pereira (2005) concluem que a supressão do SE não ocorre de maneira generalizada: há apagamento mais acentuado do clítico em contextos em que o SE possui menor valor

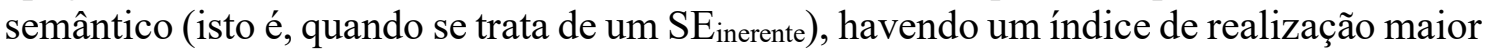
quando se trata de um $\mathrm{SE}_{\text {reflexivo: }}$

[...] Se por um lado o falante popular tende a não empregar o pronome explícito com verbos como levantar-se, por exemplo, em que não é possível distinguir, de um ponto de vista semântico-cognitivo, dois participantes no processo, o mesmo não se pode firmar com relação à categoria Reflexidade verdadeira. Nesta, que engloba os casos de reflexidade pragmaticamente não esperada, identidade referencial entre participantes que normalmente constituem entidades distintas, como em matar-se, a frequência de realização do pronome se mostra bem alta, atingindo o índice de 85\%. (RODRIGUES; PEREIRA, 2005, p. 9).

Embora considerem categorias distintas de análise, os resultados de Rodrigues e Pereira (2005) corroboram, em parte, os resultados de Nunes (1995), segundo o qual a supressão do clítico SE é mais acentuada entre os falantes do estado de São Paulo quando

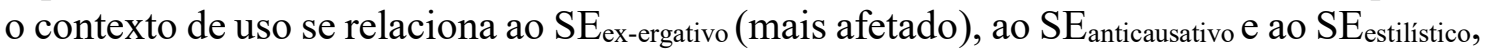
sendo menos acentuada em relação ao $\mathrm{SE}_{\text {quase-inerente (não-afetado), ao } \mathrm{SE}_{\text {inerente }} \mathrm{e} \text { ao }}$ SE reflexivo.

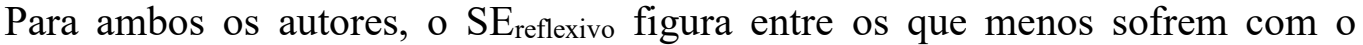
fenômeno da supressão do clítico no PB, entretanto, para Rodrigues e Pereira (2005), o

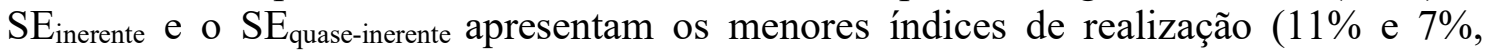
respectivamente) entre os diferentes tipos de SE, mas, para Nunes (1995), apresentam os menores índices de supressão (14\% e $0 \%$, respectivamente), i.e., $86 \%$ e $100 \%$ de realização. Em outras palavras, o $\mathrm{SE}_{\text {inerente }}$ o o $\mathrm{SE}_{\text {quase-inerente }}$ estão inversamente localizados no contínuo entre apagamento e realização do clítico pronominal nas pesquisas mencionadas. Essa diferença pode ser um reflexo da influência da escolarização na 
manutenção/supressão do clítico, pois, enquanto Rodrigues e Pereira (2005) trabalham com dados referentes às condições de uso do clítico pronominal na fala popular da zona rural, oriundos exclusivamente de entrevistas, Nunes (1995) utiliza dados de entrevistas com informantes paulistanos escolarizados e dados de registros formais escritos.

Por fim, em relação à região Sul, Freitag (2003, 2006), Madureira (2002), Pereira (2006) e Seara (2000) defendem que há manutenção do clítico SE, especialmente o $\mathrm{SE}_{\text {inerente }}$ - que, em Florianópolis, apresenta $100 \%$ de realização - e o $\mathrm{SE}_{\text {reflexivo. Há }}$ variação, no entanto, na realização dos clíticos $\mathrm{SE}_{\text {quase-inerente }}$ (33\% de realização) e $\mathrm{SE}_{\text {estilístico }}(40 \%$ de realização).

Observam-se, desse modo, algumas dicotomias durante a comparação desses estudos. Por exemplo: (i) enquanto alguns autores defendem que o $\mathrm{SE}_{\text {inerente }}$ possui os menores índices de realização (RODRIGUES; PEREIRA, 2005), outros defendem que são os que possuem o maior índice de realização (D'ALBUQUERQUE, 1984; NUNES, 1995); (ii) enquanto alguns autores defendem que há manutenção do uso do SE no Nordeste (MELLO, 2009; OLIVEIRA, 2006), outros defendem que também nessa região há supressão do SE (GONDIM, 2011).

Essas conclusões apresentadas e os apontamentos de diversos pesquisadores que têm se dedicado ao estudo do comportamento do clítico pronominal, sob diferentes perspectivas de análise (GALVES, 2001; MADUREIRA, 2002; NUNES, 1990, 1991; PEREIRA, D., 2006, 2007; SEARA, 2000, entre outros), confirmam a variação existente no PB em relação ao emprego do SE: dada a grande extensão territorial do Brasil, o uso do clítico SE apresenta, além de diferenças intercontinentais, comportamentos distintos conforme a região do país e pode ocorrer, inclusive, na fala de um mesmo indivíduo.

Em face dessas considerações sobre a variação do uso dos VP no Brasil, considera-se relevante averiguar, heuristicamente, a percepção dos falantes do interior do estado de São Paulo sobre as possibilidades de uso dos verbos pronominais, especialmente no que concerne à realização dos verbos $+\mathrm{SE}_{\text {inerente, }}$ considerados os únicos verbos pronominais que ocorrem no léxico - diferentemente dos demais, que preenchem posições argumentais (LENHARO, 2014). A próxima seção apresenta os resultados obtidos com a aplicação de um questionário online realizado para esse fim.

\section{A percepção de falantes paulistas sobre realizações de verbos pronominais}

A percepção dos falantes do interior do estado de São Paulo sobre as possibilidades de uso dos VP foi observada através dos dados oriundos da aplicação de um questionário online, elaborado e aplicado por meio do site SurveyMonkey. ${ }^{2}$

Uma vez que não se objetiva analisar os fatores extralinguísticos (LABOV, 2001) que atuam no uso ou no apagamento do clítico e que este estudo se insere em um contexto (não variacionista) maior de pesquisa (dentro do domínio linguístico-computacional, que trabalha fundamentalmente com a norma culta da língua), o questionário foi aplicado a jovens universitários (incluindo alguns pós-graduandos e professores) das seguintes instituições: (a) Universidade Estadual Paulista (UNESP) - Araraquara, SP; (b)

\footnotetext{
${ }^{2}$ O site SurveyMonkey, disponível em: <http://pt.surveymonkey.com/>, foi escolhido para a realização dessa pesquisa pois disponibiliza ferramentas que possibilitam a criação de testes virtuais de julgamento semântico para a coleta de dados e a geração de relatórios sobre os dados coletados.
} 
Faculdade de Tecnologia (FATEC) - Mococa, SP; (c) Instituto Municipal de Ensino Superior de Bebedouro (IMESB) - Bebedouro, SP; (d) Centro Universitário UNIFAFIBE - Bebedouro, SP. Ao todo, 75 voluntários se propuseram a participar. Desses, a maioria (64\%) possui entre 18 e 25 anos. Entre os demais: 22,67\% possuem entre 16 e 35 anos e $13,33 \%$ possuem mais de 35 anos.

O questionário foi confeccionado com realizações, oriundas do córpus composto por textos da internet, de 23 verbos citados como exemplos de VP (de diversos tipos) por diferentes autores (BECHARA, 2009; MELLO, 2009; NUNES, 1995; SEARA, 2000, entre outros). São eles: adaptar-se, afundar-se, ajoelhar-se, apaixonar-se, arrependerse, atrever-se, comportar-se, concentrar-se, culpar-se, dedicar-se, esbaldar-se, esforçarse, espantar-se, esquecer-se, ferir-se, importar-se, interessar-se, lembrar-se, magoar-se, queixar-se, refugiar-se, sentir-se e suicidar-se. Esses exemplos incluem a atualização e a supressão do clítico SE. Além disso, o questionário continha distratores. Para cada questão, o voluntário deveria responder qual era a probabilidade de uso das frases: (i) muito alta, (ii) alta, (iii) moderada, (iv) baixa ou (v) muito baixa. Os parágrafos seguintes apresentam os resultados obtidos.

Para o verbo afundar-se, verbo $+\mathrm{SE} E_{\text {inerente }}$ com o sentido de 'perder-se' - que possui uma contraparte não pronominal, afundar, com sentidos diferentes (como 'colocar no fundo' e 'fazer submergir') -, a supressão do clítico (06) não foi considerada um problema para $43,24 \%$ dos informantes: $32,43 \%$ afirmaram haver probabilidade alta de utilização.

(06) O filme conta a história do traficante João Estrela, jovem nascido em berço de ouro que afundou nas drogas e passou a traficar.

Para o verbo apaixonar-se, verbo+SEinerente com o sentido de 'encher-se de paixão (um sentimento forte)', foram avaliados dois contextos. No primeiro, sem o clítico SE (07), a probabilidade de uso é moderada (27,03\%), sendo os índices de probabilidade baixa/muito baixa $(41,89 \%)$ maiores que os de probabilidade alta/muito alta $(31,08 \%)$. No segundo, com a realização do clítico (08), a probabilidade alta/muito alta foi a opção da maioria dos informantes $(52,11 \%)$, com $28,17 \%$ de probabilidade baixa/muito baixa e $19,72 \%$ de moderada.

Sim, estamos aqui só faz 3 dias e já apaixonei pelo lugar.

O Vagabundo se apaixonou pela Princesa.

Para o verbo refugiar-se, verbo $+\mathrm{SE}_{\text {inerente }}$ sem contraparte transitiva, com o sentido de 'procurar abrigo em lugar seguro/com alguém', foi avaliado um contexto transitivo, em que "X refugiou $Y$ " (09) - para adequá-lo à norma culta, seria necessária uma perífrase ("X forneceu refúgio a $Y$ ") ou uma paráfrase ("Y refugiou-se com $X$ "). $56,76 \%$ dos voluntários indicaram uma probabilidade de uso baixa/muito baixa, $27,03 \%$ uma probabilidade moderada e 16,21\%, alta/muito alta. Em outras palavras, a tendência de pessoas com alta escolarização utilizarem construções como (09), em que há, além da

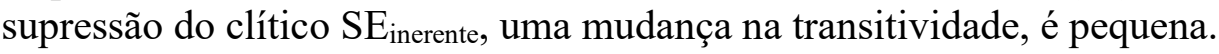

(09) Governo Lula refugiou padre das Farc por afinidade política. 
$\mathrm{O}$ verbo arrepender-se, verbo $+\mathrm{SE}$ inerente sem contraparte transitiva, com o sentido de 'sentir pesar sobre alguma ação/decisão', foi avaliado em um contexto de uso não prototípico, com supressão do SE (10). A tendência de sua utilização nesse contexto é pequena: $75,67 \%$ de probabilidade baixa/muito baixa, $12,16 \%$ de probabilidade moderada e também de alta/muito alta.

Você arrepende de ter pedido o Ronaldinho na seleção?

$\mathrm{O}$ verbo adaptar-se, que também pode ser realizado transitivamente com um complemento direto ou indireto, com o sentido de 'tornar $\mathrm{X}$ harmonioso/ajustado (com Y)', foi avaliado, em dois contextos, com o sentido de 'tornar-se familiar com uma nova

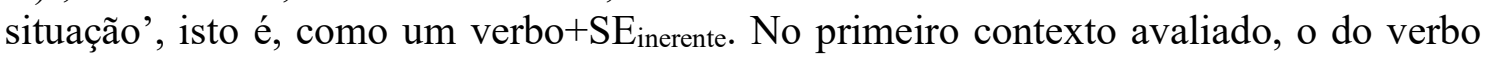
sem o clítico (11), não houve grande aceitação: para $74,32 \%$ dos informantes a probabilidade é baixa/muito baixa; para $13,51 \%$, moderada; e para $12,17 \%$ alta/muito alta. No segundo, com o verbo em sua realização prototípica, com o clítico (12), a probabilidade é de: $63,77 \%$ alta/muito alta; $24,64 \%$ moderada e $11,59 \%$ baixa/muito baixa.

(11) Minha filha entrou para a creche com 4 meses e adaptou bem.

(12) Os brasileiros se adaptaram às novas regras da ortografia?

$\mathrm{O}$ verbo suicidar-se, um verbo $+\mathrm{SE}_{\text {inerente }}$ que não possui um complemento preposicionado, com o sentido de 'tirar a própria vida', foi avaliado sem o clítico (13). Embora frequentemente empregado sem o clítico em frases de diversos sites da internet, incluindo os de jornais, como o do questionário, há rejeição por parte dos voluntários para o contexto da pesquisa: $60,81 \%$ consideram baixa/muito baixa a sua probabilidade de uso; $25,68 \%$ alta/muito alta e $13,51 \%$ moderada.

(13) Caso de homem que matou mulher e suicidou será investigado pela $3^{\mathrm{a}} \mathrm{DP}$.

$\mathrm{O}$ verbo queixar-se, verbo+SE $\mathrm{S}_{\text {inerente }}$ com o sentido de 'reclamar de algo', foi avaliado em dois contextos: no primeiro, o prototípico, com o clítico (14), há $64,86 \%$ de probabilidade alta/muito alta, $22,97 \%$ de moderada e $12,16 \%$ de baixa/muito baixa. No segundo, sem o clítico (15), a tendência de uso se inverte: $59,16 \%$ de probabilidade baixa/muito baixa, $21,13 \%$ de moderada e $19,72 \%$ de alta/muito alta.

(14) Médicos se queixam de infraestrutura e abandonam programa "Mais médicos".

(15) Ele queixou ao Ministério Público que carros de propaganda estavam passando com o som nas alturas, perturbando os moradores em geral.

O verbo esforçar-se, com o sentido de 'empenhar grande força de trabalho para a

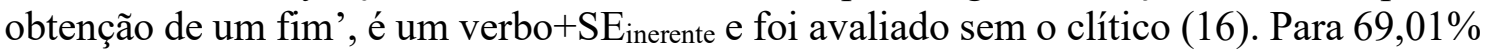
dos participantes, a probabilidade de uso é baixa/muito baixa; para $21,13 \%$, moderada; e para $9,86 \%$, alta/muito alta.

(16) Herrera até que esforçou bastante, mas acabou ficando isolado depois da expulsão do meia Eduardo, no início da partida. 
O verbo espantar - embora permita uma leitura causativa, com os sentidos de 'assustar, causar espanto ou afugentar', na qual um sujeito Agente espanta um Paciente através do uso de um Instrumento -, com o sentido de 'ficar admirado ou assustado

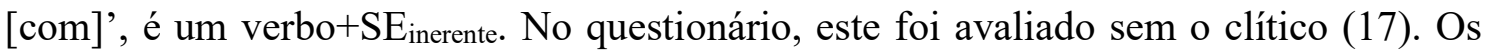
índices de probabilidade de uso obtidos são: $56,34 \%$ de baixa/muito baixa, $22,54 \%$ de alta/muito alta e $21,13 \%$ de moderada.

(17) Não espante se desta vez os caras resolverem enfiar alienígenas malvados na história.

Índices semelhantes foram observados para o verbo atrever-se, um verbo $+\mathrm{SE}_{\text {inerente }}$ com o sentido de 'fazer afronta [a]', em um contexto de uso não prototípico (18): $54,93 \%$ de probabilidade baixa/muito baixa; $25,36 \%$ de alta/muito alta e $19,72 \%$ de moderada.

Como você atreve a me desobedecer?

$\mathrm{O}$ verbo ferir-se, um verbo $+\mathrm{SE}_{\text {reflexivo }}$ (pois admite leitura causativa sem alteração semântica e admite o redobro com a expressão a si mesmo (LENHARO, 2014)) com o sentido de 'causar ferimento [em]', foi avaliado em um contexto de uso pronominal (19): $60,57 \%$ dos informantes consideram a probabilidade de uso alta/muito alta e $19,72 \%$ a consideram moderada, ao lado de outros $19,72 \%$ que a consideram baixa/muito baixa.

Não importa quem te feriu... O importante é que você sarou.

O verbo interessar-se, com o sentido de 'adquirir interesse [por]', é um verbo $+\mathrm{SE}_{\text {inerente. }}$ Seu uso prototípico, por isso, pede a atualização do SE. Difere da realização transitiva (direta e indireta) que o verbo interessar pode atualizar, com sentidos diferentes do pronominal, tais como o de "atrair, provocar a curiosidade ou o interesse" - transitivo direto (WEISZFLOG, 1998). No questionário, foi avaliado como verbo $+\mathrm{SE}_{\text {inerente }}$ com apagamento do clítico (20): $52,18 \%$ dos informantes consideram baixa/muito baixa a sua probabilidade de uso; $28,98 \%$ a consideram alta/muito alta e $18,84 \%$ moderada.

Interessou no imóvel?

Situação semelhante é a do verbo importar-se, que, com o sentido de 'ter

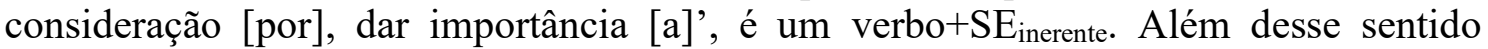
pronominal, o verbo importar pode ser atualizado transitivamente (com complemento direto ou indireto) ou intransitivamente, com outros sentidos. Avaliado com a supressão do SE em sua realização pronominal (21), apresenta $66,20 \%$ de probabilidade baixa/muito baixa; $21,12 \%$ alta/muito alta e $12,68 \%$ moderada.

Eu penso que você importa comigo, mas na verdade você nem lembra que eu existo!

O verbo sentir-se, com o sentido de 'experimentar uma sensação física ou

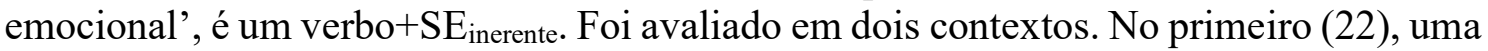
realização prototípica, os percentuais de probabilidade de uso são: $40,58 \%$ de alta/muito alta; $37,68 \%$ de baixa/muito baixa e $21,74 \%$ de moderada. No segundo, com a supressão do clítico (23), 76,81\% dos informantes consideram a probabilidade de uso baixa/muito baixa, $15,94 \%$ moderada e 7,25\% alta/muito alta. Comparando-se os dados dos dois 
contextos de uso, conclui-se que, apesar de o contexto prototípico não ser avaliado positivamente, o contexto de uso não prototípico é avaliado negativamente, sendo alto o percentual de improbabilidade de uso.

Oh! Me sinto só. Eu me sinto tão seu.

(23) Apesar da cautela com seu ombro, Pedrosa já sente bem e está animado para a continuação do campeonato.

O verbo ajoelhar-se, com o sentido abstrato de 'colocar-se em posição inferior', é um verbo $+\mathrm{SE}_{\text {inerente. }} \mathrm{O}$ contexto avaliado (24) prediz um estado de coisas em que $\mathrm{X}$ reconhece o talento de $\mathrm{Y}$ e se curva, figurativamente, em sinal de respeito, a Y. Trata-se de uma realização não prototípica, pois há supressão do clítico. Os índices mostram que há $52,17 \%$ de probabilidade de uso baixa/muito baixa; $27,54 \%$ de probabilidade moderada e 20,29\% de probabilidade alta/muito alta.

Anthony Hopkins ajoelha para Bryan Cranston, protagonista da série Breaking Bad.

O verbo concentrar-se, com o sentido de 'focar a atenção em algo', é um verbo $+\mathrm{SE}_{\text {inerente }}$ - diferentemente de concentrar, com os sentidos de 'reunir' e 'tornar mais denso', por exemplo, que é um verbo não pronominal construído com um complemento direto. No teste, em um contex to não prototípico (25), apresenta: $39,13 \%$ de probabilidade alta/muito alta; $39,13 \%$ de probabilidade baixa/muito baixa e $21,74 \%$ de probabilidade moderada. Isoladamente, a probabilidade de uso alta apresenta o maior índice $(24,64 \%)$, mas há certo equilíbrio entre os índices de todas as probabilidades - 14,49\% muito alta; $21,74 \%$ moderada; $18,84 \%$ baixa e $20,29 \%$ muito baixa -, o que pode indicar que, apesar de haver resistência quanto ao contexto de realização não prototípica do verbo, a supressão do SE é aceitável entre os falantes avaliados.

Talita do céu, para de vender ingressos e concentra nos estudos menina!

O verbo esquecer, por sua vez, pode ser construído (com e sem alteração semântica) de diferentes maneiras: transitivamente (com complemento direto ou indireto), intransitivamente e pronominalmente. Com o sentido de "perder algo da memória', é um verbo+SEinerente. Assim, para que (26) estivesse de acordo com a norma culta do português, seria necessário retirar a preposição (X não esqueceu o aniversário de $\mathrm{Y}$ ), transformando-o em um verbo transitivo direto, ou adicionar o clítico SE na construção ( $\mathrm{X}$ não se esqueceu do aniversário de $\mathrm{Y}$ ). Do modo como foi construída, embora o maior índice individual de probabilidade de uso da sentença seja o muito baixo (com 26,09\%), quando os índices são agrupados, a probabilidade alta/muito alta representa $39,13 \%$ do total, a moderada $23,19 \%$ e a baixa/muito baixa $37,68 \%$, isto é, a tendência de uso do contexto não prototípico é maior que a de sua não utilização.

Neymar não esqueceu do aniversário de sua namorada, Bruna Marquezine.

O verbo comportar-se, com o sentido de 'proceder de determinada maneira', é um verbo $+\mathrm{SE}_{\text {inerente. }}$ Difere semanticamente de comportar, transitivo direto, que atualiza, entre outros, os sentidos de 'conter em si' e 'possuir capacidade para receber ou acomodar [algo]'. No teste, foi avaliado com o apagamento do clítico (27). Os índices de probabilidade de uso são: $66,20 \%$ baixa/muito baixa, $21,13 \%$ moderada e $12,67 \%$ 
alta/muito alta. Dada a diferença percentual, pode-se afirmar que a realização não prototípica do verbo é avaliada negativamente pelos falantes.

Os avaliadores vão observar como você comporta nos mínimos detalhes, isso inclui gestos.

$\mathrm{O}$ verbo culpar-se, um verbo $+\mathrm{SE}$ inerente com o sentido de 'sentir/possuir culpa [por]', difere do transitivo (direto ou indireto) culpar ('atribuir culpa [a]'). No teste, dois contextos de uso, com o sentido pronominal, foram avaliados. No primeiro, com realização do SE (28), os índices são: $56,33 \%$ de probabilidade alta/muito alta; $26,76 \%$ de baixa/muito baixa e 16,90\% de moderada. No segundo, com supressão do clítico (29), $69,57 \%$ de probabilidade baixa/muito baixa, $18,84 \%$ de alta/muito alta e $11,59 \%$ de moderada.

(29) Você sente que nada funciona como você queria? Você culpa por isso? Sua autoestima é baixa?

Por fim, o verbo magoar-se, um verbo $+\mathrm{SE}$ inerente com sentido de 'sentir tristeza, desgosto'. Avaliado sem o clítico (30), obteve 43,48\% de probabilidade de uso baixa/muito baixa; $39,13 \%$ de alta/muito alta e 17,39\% de moderada. Há, portanto, certo equilíbrio entre os índices obtidos, o que pode indicar que a ausência do clítico com o verbo magoar não é avaliada negativamente pelos falantes paulistas que participaram da pesquisa.

(30) Não quero mais saber, magoei com todos vocês.

Com base nesses resultados obtidos com a aplicação do questionário, podem ser traçadas algumas considerações sobre o uso dos VP pelo grupo de paulistas, tais como as apresentadas a seguir. Os índices de probabilidade de uso das sentenças avaliadas em (i) alto/muito alto, (ii) moderado e (iii) baixo/muito baixo, para a análise, serão sintetizados na Tabela 1, onde, consoante cada verbo e o contexto avaliado, na coluna "Aceitação de uso", serão agrupados respectivamente em (i) "sim", (ii) "talvez" e (iii) "não". Os verbos podem ser reunidos, assim, com base nos índices de aceitação, nos seis seguintes grupos:

1) Verbos que foram analisados em dois contextos distintos, o da realização e o da supressão do clítico SE. Pode ser subdividido em três grupos, conforme o comportamento dos verbos que os constituem:

1a) Verbos adaptar-se, culpar-se e queixar-se, cuja realização do clítico é avaliada positivamente (com 63,77\%, 56,33\%, 64,86\%, respectivamente, de avaliação positiva) e a supressão é avaliada negativamente (com 74,32\%, 69,57\% e 59,16\%, respectivamente, de rejeição).

1b) Verbo apaixonar-se, com maior aceitabilidade para a supressão do clítico (em relação ao Subgrupo 1a).

1c) Verbo sentir-se, com alto índice de rejeição da supressão do SE $(76,81 \%)$. Diferentemente dos verbos do Subgrupo 1a, os índices de probabilidade são mais próximos entre si, com $40,58 \%$ de aceitação e $37,68 \%$ de rejeição.

2) Verbo ferir, o único verbo+SEreflexivo do questionário, avaliado com $60,57 \%$ de aceitação em sua realização pronominal. 
3) Verbos ajoelhar-se, arrepender-se, atrever-se, comportar-se, esforçar-se, espantarse, importar-se, interessar-se, refugiar-se e suicidar-se, que se distinguem dos verbos do Grupo 1(a) por não terem sido avaliados em dois contextos distintos (avaliados em contextos de supressão do clítico). Assim como os verbos do Subgrupo 1a, apresentam altos índices de rejeição.

4) Verbo concentrar-se, cujo percentual de aceitação de uso sem o clítico é exatamente igual ao percentual de rejeição: $39,13 \%$.

5) Verbo magoar-se, que, apesar de apresentar o índice de rejeição maior que o de aceitação, não apresenta uma diferença muito grande entre os percentuais (respectivamente, $43,48 \%$ e $39,13 \%$ ).

6) Verbos afundar-se e esquecer-se, que apresentam índices de aceitação de uso com supressão do clítico SE $(43,24 \%$ e $39,13 \%$, respectivamente) maiores que os de rejeição $(32,44 \%$ e $37,68 \%$, também respectivamente).

Tabela 1. Agrupamento dos verbos do questionário conforme aceitação de uso

\begin{tabular}{c|c|c|c|c}
\hline \multirow{2}{*}{ Verbo } & \multirow{2}{*}{ Clítico SE } & \multicolumn{3}{|c}{ Aceitação de uso } \\
\cline { 3 - 5 } & & Sim & Talvez & Não \\
\hline \multirow{2}{*}{ adaptar-se } & sem & $12,17 \%$ & $13,51 \%$ & $74,32 \%$ \\
& com & $63,77 \%$ & $24,64 \%$ & $11,59 \%$ \\
\hline \multirow{2}{*}{ culpar-se } & sem & $18,84 \%$ & $11,59 \%$ & $69,57 \%$ \\
& com & $56,33 \%$ & $16,90 \%$ & $26,76 \%$ \\
\hline \multirow{2}{*}{ queixar-se } & sem & $19,72 \%$ & $21,13 \%$ & $59,16 \%$ \\
& com & $64,86 \%$ & $22,97 \%$ & $12,16 \%$ \\
\hline \multirow{2}{*}{ apaixonar-se } & sem & $31,08 \%$ & $27,03 \%$ & $41,89 \%$ \\
& com & $52,11 \%$ & $19,72 \%$ & $28,17 \%$ \\
\hline sentir-se & sem & $7,25 \%$ & $15,94 \%$ & $76,81 \%$ \\
& com & $40,58 \%$ & $21,74 \%$ & $37,68 \%$ \\
\hline ferir & com & $60,57 \%$ & $19,72 \%$ & $19,72 \%$ \\
\hline ajoelhar-se & sem & $20,29 \%$ & $27,54 \%$ & $52,17 \%$ \\
arrepender-se & sem & $12,16 \%$ & $12,16 \%$ & $75,67 \%$ \\
atrever-se & sem & $25,36 \%$ & $19,72 \%$ & $54,93 \%$ \\
comportar-se & sem & $12,67 \%$ & $21,13 \%$ & $66,20 \%$ \\
esforçar-se & sem & $9,86 \%$ & $21,13 \%$ & $69,01 \%$ \\
espantar-se & sem & $22,54 \%$ & $21,13 \%$ & $56,34 \%$ \\
importar-se & sem & $21,12 \%$ & $12,68 \%$ & $66,20 \%$ \\
interessar-se & sem & $28,98 \%$ & $18,84 \%$ & $52,18 \%$ \\
refugiar-se & sem & $16,21 \%$ & $27,03 \%$ & $56,76 \%$ \\
suicidar-se & sem & $25,68 \%$ & $13,51 \%$ & $60,81 \%$ \\
\hline concentrar-se & sem & $39,13 \%$ & $21,74 \%$ & $39,13 \%$ \\
\hline magoar-se & sem & $39,13 \%$ & $17,39 \%$ & $43,48 \%$ \\
\hline afundar-se & sem & $43,24 \%$ & $24,32 \%$ & $32,44 \%$ \\
esquecer-se & sem & $39,13 \%$ & $23,19 \%$ & $37,68 \%$ \\
\hline & & & &
\end{tabular}

Fonte: Elaboração própria

Com base nesses dados, constata-se que, na maior parte das situações observadas, (i) nos contextos em que há a realização dos verbos pronominais com a presença do clítico, a avaliação é positiva e (ii) nos contextos em que há a realização dos verbos pronominais com a supressão do clítico SE, a avaliação é negativa. Desse modo, embora se confirme a variação de uso dos verbos pronominais quanto à realização e à supressão 
do clítico SE, a presença do SE, como estabelece a norma culta do português, ainda é a forma de maior prestígio na comunidade linguística avaliada.

Além disso, a observação desses resultados faz com que a seguinte indagação surja: a existência de contrapartes não pronominais para os verbos $+\mathrm{S} E_{\text {inerente }}$ permite (talvez por processos de analogia) que eles sejam realizados sem o clítico? Ao se relacionar a existência de contrapartes não pronominais com os índices de aceitação (alta/muito alta) de uso dos contextos em que há apagamento do SE, nota-se que: (i) os seis primeiros verbos (afundar-se, concentrar-se, esquecer-se, magoar-se, apaixonar-se e interessar-se), cujos contextos avaliados exemplificam realizações não prototípicas, possuem uma contraparte não pronominal e apresentam os maiores índices de aceitação do contexto avaliado; (ii) os verbos suicidar-se e atrever-se, por outro lado, são os sétimo e oitavo verbos cujos contextos avaliados obtiveram os maiores índices de aceitação, mesmo sendo contextos não prototípicos, e ambos não possuem uma contraparte não pronominal; (iii) os dois piores índices de aceitação dos contextos avaliados são os dos verbos esforçar-se e sentir-se, verbos que possuem contrapartes não pronominais. Portanto, não é possível considerar a existência de uma contraparte não pronominal como um parâmetro que regule as realizações não prototípicas dos verbos $+\mathrm{SE}_{\text {inerente. }}$

\section{Considerações finais}

Conforme salientado anteriormente, algumas inovações linguísticas tendem a ocorrer primeiro entre os mais jovens (e, às vezes, entre os indivíduos socioeconomicamente menos favorecidos que, muitas vezes, possuem maior dificuldade para ter acesso à educação institucionalizada). Algumas dessas inovações permanecerão restritas a determinados grupos, muitas vezes estigmatizadas e marginalizadas, e não se difundirão para toda a comunidade. Portanto, serão variações linguísticas que não se tornarão mudanças linguísticas de fato implementadas na língua.

A revisão bibliográfica apresentada ao longo deste estudo fornece evidências que confirmam a variação existente no Brasil em relação ao emprego do clítico SE: em determinadas regiões do país há maior utilização e aceitação do apagamento do clítico pronominal, em outras, no entanto, há resistência a esse fenômeno linguístico. Do mesmo modo, alguns itens lexicais parecem 'permitir' de modo mais tranquilo a supressão do $\mathrm{SE}$, enquanto outros tendem a ser mais 'conservadores' quanto ao uso do clítico.

Pode ser que se trate de uma mudança linguística em curso. No entanto, com base nos dados do teste de percepção dos falantes paulistas (universitários) acerca dessa variação, é possível dizer que, por hora, não é uma inovação que tenha alcançado todos os falantes, pois há resistência entre alguns dos indivíduos pesquisados.

\section{REFERÊNCIAS}

BAKHTIN, M. Marxismo e filosofia da linguagem. Tradução de Michel Lahud e Yara F. Vieira. São Paulo: Hucitec, 1986.

Teoria do romance I: a estilística. Tradução de Paulo Bezerra. São Paulo: Editora $34,2015$. 
D’AlBuQUerQue, A. C. R. C. A perda dos clíticos num dialeto mineiro. Tempo Brasileiro: sociolinguística e o ensino do vernáculo. Rio de Janeiro, v. 78/79, p. 97-121, 1984.

BECHARA, E. Moderna gramática portuguesa. 37. ed. Rio de Janeiro: Nova Fronteira, 2009.

FARACO, C. A. Linguística histórica: uma introdução ao estudo da história das línguas. São Paulo: Parábola, 2014.

FREITAG, R. M. K. Uma hipótese de gramaticalização do pronome reflexivo se na fala de Florianópolis. Working papers em Linguística. UFSC - CCE, Curso de Pós-Graduação em Linguística, Florianópolis: CPGLg, n. 7, p. 59-72, 2003.

Análise quantitativa dos clíticos correferenciais na fala de Florianópolis e de Porto Alegre: discutindo evidências da afixação de SE. In: CONGRESSO INTERNACIONAL DE POLÍTICA LINGUÍSTICA NA AMÉRICA DO SUL (Cipla), 2006, João Pessoa (PB). Linguas e Povos: unidade e diversidade, p. 437-442, 2006.

GALVES, C. Ensaios sobre as gramáticas do português. Campinas: UNICAMP, 2001.

GONDIM, E. M. O uso do clítico na fala culta de Fortaleza. Entrepalavras, Fortaleza, a. 1, v. 1, n. 1, p. 37-47, ago./dez. 2011.

LABOV, W. Principles of linguistic change: internal factors. Oxford: Blackwell, 1994.

Principles of linguistic change: social factors. Oxford: Blackwell, 2001.

Padrões sociolinguísticos. São Paulo: Parábola, 2008.

LENHARO, A. C. Descrição léxico-gramatical e funcional dos verbos pronominais do português brasileiro com vistas à construção da base de verbos da wordnet brasileira e do alinhamento semântico desta à base de verbos da wordnet norte-americana. 2014. 279 f. Tese (Doutorado em Linguística e Língua Portuguesa) - Faculdade de Ciências e Letras, Universidade Estadual Paulista, Araraquara, 2014.

LIMA, B. F. Z. O percurso diacrônico das construções com o pronome se na Língua Portuguesa como um processo de gramaticalização. 2006. $130 \mathrm{f}$. Tese (Doutorado em Linguística) - Faculdade de Letras, Universidade Federal de Minas Gerais, Belo Horizonte, 2006.

MADUREIRA, E. D. Variação nas construções pronominais dos verbos psicológicos: uma decorrência de diferentes percursos históricos. In: COHEN, M. A. A. M.; RAMOS, J. M. (Org.). Dialeto mineiro e outras falas: estudos de variação e mudança linguística. Belo Horizonte: FALE/UFMG, 2002.

MELLO, F. R. Acabou-se o que era doce, quem comeu se regalou-se: uma análise do clítico se em João Pessoa na interface Sociolinguística/Gramaticalização. 2009. 322 f. Tese (Doutorado) - Centro de Ciências Humanas, Letras e Artes, Universidade Federal da Paraíba, João Pessoa, 2009.

MELO, N. S. S. O clítico se com valor reflexo ou recíproco: uma abordagem sociolinguística. 2005. 123 f. Dissertação (Mestrado em Linguística) - Instituto de Letras e Linguística, Universidade Federal de Uberlândia, Uberlândia, 2005.

MONTEIRO, J. L. Para compreender Labov. Petrópolis: Vozes, 2002. 
NUNES, J. M. O famigerado SE: uma análise sincrônica e diacrônica das construções com SE apassivador e indeterminador. 1990. 170 f. Dissertação (Mestrado em Linguística) - Instituto de Estudos da Linguagem, Universidade Estadual de Campinas, Campinas, 1990.

Ainda o famigerado SE. DELTA, v. 11, n. 2, p. 201-240, 1995.

OLIVEIRA, M. Nós se cliticizou-se? In: LOBO, T.; RIBEIRO, I.; CARNEIRO, Z.; ALMEIDA, N. (Org.). Para a História do Português Brasileiro. v. VI: novos dados, novas análises. Salvador: EDUFBA, 2006. p. 413-425.

PEREIRA, A. L. D. Os pronomes clíticos do PB contemporâneo na perspectiva teórica da Morfologia Distribuída. 2006. 215 f. Tese (Doutorado em Linguística) - UFSC, Florianópolis, 2006.

PEREIRA, D. C. Variação e mudança no uso dos pronomes reflexivos no português popular da capital paulista: uma abordagem funcionalista e cognitivista. 2007. $350 \mathrm{f}$. Tese (Doutorado em Letras) - Faculdade de Filosofia, Letras e Ciências Humanas, Universidade de São Paulo, São Paulo, 2007.

RODRIGUES, Â. C. S.; PEREIRA, D. C. Pronomes reflexivos no português popular brasileiro. In: CONGRESO INTERNACIONAL DE LA ALFAL, 14. Monterrey (Mexico), 2005. Actas... Disponível em: <www.mundoalfal.org/ cdcongreso/cd/dialectologia_sociolinguistica/rodrigues.html>. Acesso em: 12 abr. 2016.

SEARA, I. C. Estudo de uma hipótese semântico-pragmática para a omissão de clíticos pronominais. Letras de Hoje, Porto Alegre: PUCRS, v. 14, n. 119, p. 165-187, mar. 2000.

TARALLO, F. A pesquisa sociolinguística. São Paulo: Ática, 1994.

VILELA, M. Léxico e gramática. Coimbra: Livraria Almedina, 1995.

WEINREICH, U.; LABOV, W.; HERZOG, M. Fundamentos empíricos para uma teoria da mudança linguística. São Paulo: Parábola, 2006.

Recebido em: 01/09/2016

Aprovado em: 12/04/2017 